\title{
O problema das restrições teórico-analíticas nos estudos sociais da ciência e da tecnologia
}

\section{Denise Maria Nunes ${ }^{1}$}

Resenha do livro:

THOMAS, Hernán; BUCH, Alfonso (Org.). Actos, actores y artefactos: Sociologia de la tecnologia. 1. ed. Bernal: Universidad Nacional de Quilmes, 2008. 296p.

No Brasil, os estudos sociais da ciência e da tecnologia ainda encontram algumas barreiras como, por exemplo, o excesso de determinismo (seja ele social ou tecnológico) nas pesquisas existentes, sejam elas sociológicas, da área de política científica e tecnológica, ou ainda, das linhas de pesquisa chamadas CTS (ciência, tecnologia e sociedade) presentes nos mais variados campos que vão da Educação à Física, Matemática, Química, Biologia até as Engenharias. Dada a variedade de áreas de abordagens, é possível se identificar a relevância destes estudos e sua implicância em questões políticas e até mesmo territoriais. Fazer ciência é fazer política. Embora Karl Marx já chamasse atenção para o cuidado de que a ciência não se tornasse ideológica.

Quando se trata de ciência e tecnologia, encontra-se também o problema de datação de ambas, bem como o da dissociação delas. A tecnologia é anterior à ciência, uma vez que a primeira pode ser entendida como sendo artefatos, processos e até mesmo conhecimento. Porém, definir e/ou diferenciar técnica e tecnologia não é uma tarefa simples. O autor Álvaro Vieira Pinto já demonstra isso em sua obra com mais de mil páginas intitulada "O conceito de

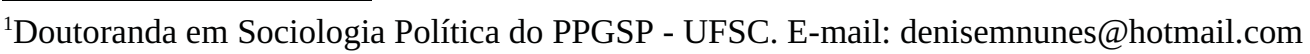


tecnologia" (PINTO, 2005). Já sobre a datação da "invenção" da ciência, o autor Bruno Latour argumenta que esta surge com a invenção do laboratório, porém é importante esclarecer de que se ciência se está falando, uma vez que as ciências sociais não têm como justificar sua origem desta forma (LATOUR, 1997).

Não existem definições últimas e definitivas sobre ciência e tecnologia, mas é importante que cada estudo apresente a definição que Ihe convém e que por sua vez, está sendo utilizada. Existem processos individuais e coletivos de apropriação da ciência e da tecnologia. E por estes motivos é preciso fugir dos determinismos.

Mas, mesmo problemas de determinismo e de definições apresentam-se de modo diluído nos estudos sociais da ciência e da técnica. Não é fácil encontrá-los como foco, destes estudos. No Brasil, é rara a teorização nesta área - a produção de metas-teoria, como teorias de médio alcance voltadas para o âmbito nacional. E além destes problemas, há aquele relacionado a falta de método. Não só faltam métodos de análise, como teorias sobre métodos específicos para estes estudos.

E este é o assunto, dirigido para a sociologia da tecnologia, que Thomas e Buch abordarão em seu livro Actos, actores y artefactos: sociologia de la tecnologia, de 2008. O livro está organizado em seis capítulos, onde os organizadores apresentam uma seleção de artigos de autores considerados referências hoje, no campo da sociologia da tecnologia. Dentre eles estão Wiebe E. Bijker, Michel Callon, Thomas P. Hughes e Trevor J. Pinch. O livro tem como objetivo principal apresentar "uma série de leituras que contêm ferramentas de análises e conceitos teóricos gerados com o objetivo de compreender porque tanto as tecnologias como as sociedades são como são, e não são de outra maneira" (THOMAS; BUCH, 2008, p. 13).

$\mathrm{O}$ artigo de Henrik Bruun com Janne Hukkinen e o de Hernán Thomas, buscam realizar uma integração e um aprofundamento das propostas teóricas de Bijker, Callon, Hughes e Pinch, na tentativa de 
superar restrições analíticas presentes nos argumentos destes autores.

Trata-se não só de um livro interessante por seu conteúdo, mas extremamente útil em termos metodológicos, justamente por disponibilizar ferramentas conceituais e, também, por debatê-las evidenciando suas diferenças, vantagens e falhas, tudo com base em argumentos sensatos e inteligentes capazes de levar o leitor, estudioso da área, a rever seus conceitos e métodos de análise.

Esta obra apresenta uma leitura agradavelmente densa. Com uma introdução escrita a seis mãos (de Hernán Thomas, Mariano Fressoli e Alberto Lalouf) e um senso de humor peculiar, os autores apresentam argumentos envolventes e questionamentos que são ao mesmo tempo instigantes e intrigantes, que nos levam a refletir sobre nossas práticas cotidianas e a influência da tecnologia nelas.

Os autores chamam atenção para a interconexão e a interdependência das tecnologias e para o fato de que as ciências sociais raramente voltam suas temáticas para esse assunto. Destacam que a questão sociotécnica ainda não ocupa um espaço relevante tanto na formação dos cientistas bem como dos intelectuais. Sendo assim, os autores pretendem que a leitura deste material remeta a duas possibilidades: 1) a de romper com as formas que apresentam um sentido comum sobre a tecnologia e 2) "a problematização do papel que desempenham as tecnologias nas diversas disciplinas orientadas a explicar processos sociais, culturais, políticos e econômico" (ibidem, p. 16). Sendo assim, passemos então para "[...] a difícil arte de pensar o pensado [...]"2, seguindo agora para o conteúdo de cada artigo isoladamente.

O primeiro artigo é de Trevor Pinch e Wiebe E. Bijker, intitulado La construcción social de hechos y de artefactos: o acerca de cómo la sociologia de la tecnologia pueden beneficiarse mutuamente. O artigo

\footnotetext{
${ }^{2}$ ASSIS, Joaquim Maria Machado de. Teoria do medalhão. Disponível em: $<\underline{\text { http://www.literaturabrasileira.ufsc.br/arquivos/texto/0006-02393.html\#tteoria do medalhao abaixo> }}$ Acesso em: 15/09/2010
} 
parte da análise da bicicleta e traz a noção de flexibilidade interpretativa como uma ferramenta para a análise de artefatos tecnológicos nos processos de disputas e negociações que envolvem seu desenvolvimento. Relacionam este artefato a outros movimentos sociais e o risco de seu uso. A noção de flexibilidade interpretativa implica em flexibilidade artefatual e no modo como cada grupo relevante apresenta diferentes versões a um mesmo artefato.

No capítulo sobre "La construcción social de La baquelita: hacia uma teoria de la invención", Wiebe E. Bijker analisa o processo de produção e invenção da baquelita como substituto da madeira e do marfim. Inicia seu artigo com a descrição da história do plástico antes da baquelita. O autor retoma o conceito de flexibilidade interpretativa. Como ferramenta teórica nesta análise, traz também a noção de marco tecnológico, que está ligada à caracterização, ao funcionamento e à estética de artefatos arquetípicos e às relações problema-solução no que se refere ao funcionamento dos mesmos de acordo com o posicionamento dos grupos sociais relevantes neste contexto.

Thomas P. Hughes, por sua vez, em seu artigo “La evolución de los grandes sistemas tecnológicos", apresenta inicialmente a definição de sistemas tecnológicos, um dos conceitos-ferramentas de sua teoria. Hughes propõe uma releitura dos conceitos existentes nos estudos sobre mudanças tecnológicas. Em seus sistemas tecnológicos, elementos heterogêneos são incorporados de acordo com o construtor do sistema. Ao falar da expansão dos sistemas, Hughes apresenta outros dois conceitos de igual relevância em sua teoria que são o conceito de salientes reversas (reversal salients) e de estilo tecnológico, o qual, por sua vez, deveria estar atrelado à noção de transferência tecnológica. Segundo Hughes, na medida em que os sistemas amadurecem, eles adquirem estilo e momentum (outro conceito importante apresentado), onde o estilo deve ser pensado com a transferência e o momentum com o crescimento, a 
competência e a consolidação do sistema. O autor analisa os conceitos de invenção, inventor, desenvolvimento e inovação. Para ele, o empresário passa a ser um construtor de sistemas e os historiadores e sociólogos deveriam se voltar para a história dos sistemas tecnológicos a partir de padrões e conceitos aplicáveis.

O artigo de Michel Callon "La dinâmica de las redes tecnoeconomicas" expõe claramente uma abordagem teórico metodológica unindo a sociologia da tecnologia e a economia envolvida nos processos de mudança tecnológica. O autor segue o princípio da simetria radical de Bruno Latour, e suas redes pressupõem um alinhamento entre atores humanos e não-humanos. Callon questiona as teorias convencionais sobre a trama que envolve atores, cientistas e toda a rede tecno-economica em questão. Em seus argumentos, apresenta as noções de redes tecno-economicas, intermediários, atorrede, tradução, alinhamento e coordenação, além do princípio da simetria radical já mencionado. Para o autor, as redes tecnoeconômicas estão organizadas em três pólos: o pólo econômico, o pólo técnico e o pólo do mercado. E o intermediário é aquele que estabelece uma relação (econômica) através de um produto em sua produção e demanda. O intermediário é qualquer coisa que passa de um ator a outro e que constitui a forma e a substância da relação estabelecida entre eles. Artigos científicos, programas de computador, artefatos tecnológicos e etc, podem ser considerados intermediários (THOMAS; BUCH, 2008, p. 150). A tradução, por sua vez, é uma operação estabelecida entre entidades que podem ser atores e intermediários. Para Callon, as redes apresentam dinâmicas e é possível segui-las, pois formam uma composição que mescla atores humanos e não humanos. Esclarece ainda que as redes não estão nos atores, mas sim que eles as produzem.

Partindo para a parte final do livro, chega-se ao penúltimo capítulo de Henrik Brunn e Janne Hukkinen, intitulado “Cruzando fronteras: um diálogo entre três formas de compreender el cambio 
tecnológico". Os autores, aqui, pensam nas possibilidades de integração e complementação entre as abordagens de Callon (TAR) e Bijker (CTS) e nas conceitualizações feitas pelas teorias econômicas neoschumpeterianas evolucionistas (economia evolucionista - EE) sobre mudanças tecnológicas de Christopher Freeman, Nathan Rosenberg e Richard Nelson.

São propostas correlações e potenciais explicativos no que se refere a diferentes níveis do processo de mudança tecnológica, desde a invenção, a inovação, a difusão e a produção. Para estes autores, os economistas evolucionistas observam o conhecimento como um componente básico da dinâmica econômica (THOMAS; BUCH, 2008, p. 189). Ao abordar a construção social da tecnologia, os autores referem-se aos pensadores Trevor Pinch e Wiebe Bijker que moldaram seus argumentos com base na sociologia do conhecimento científico. Esta, por sua vez, criticava a sociologia da ciência institucionalizada. Em sua abordagem, eles retomam destes últimos a noção de flexibilidade interpretativa e clausura. Para eles, o conceito de clausura permite observar os processos como se criam paradigmas tecnológicos e suas trajetórias. É analisado também o conceito de marco tecnológico de Bijker para descrever como diferentes grupos sociais interpretam os artefatos. Com relação à teoria ator-rede (TAR), os autores retomam a origem da mesma e consideram que esta contribui com ideias úteis e complementares à perspectiva proposta por Pinch e Bijker. Mas, esclarecem que, para isso, é preciso ler a TAR omitindo-se alguns de seus fundamentos filosóficos-metodológicos. Na tentativa de construir um marco de diálogo entre a EE, CTS e a TAR, os autores concluem que os três aportes teóricos complementam-se e abrem perspectivas para novos desenvolvimentos analíticos. São enfoques que dialogam entre si e que o fazem sob diferentes aspectos da tecnologia e do processo de mudança tecnológica. 
Por fim, o livro traz o artigo de Hernán Thomas, intitulado "Estructuras cerradas versus procesos dinâmicos: trayectorias y estilos de innovación e cambio tecnológico". O autor busca com esse artigo encerrar o livro realizando uma revisão das teorias construtivistas disponíveis propondo uma série de conceitos com o objetivo de superar restrições analíticas destas abordagens e adequar “as ferramenta teóricas para a análise simétrica-socio-historicamente situada - de processos de mudança tecnológica tanto em países desenvolvidos como subdesenvolvidos" (THOMAS; BUCH, 2008). Para o autor, as noções de mudança tecnológica e inovação tem se modificado nas últimas décadas. Em sua análise, construiu uma triangulação teórica, modificando conceitos da sociologia da tecnologia e economia da mudança tecnológica, com o objetivo de propor um conjunto de conceitos sócio-técnicos: dinâmica e trajetória sócio-técnica, estilos sócio-técnicos, resignificação de tecnologias, conhecimentos genéricos, processos de adequação sócio-técnica, entre outros, úteis para a compreensão do processo de desenho, produção e utilização de tecnologias na América Latina (THOMAS; $\mathrm{BUCH}, 2008$, p. 218). Thomas conclui que os estudos que apresentou permitem compreender a realidade de determinadas regiões, para ele a análise de fenômenos locais tem aberto a possibilidade de revisar criticamente as teorias disponíveis, complementá-las e desenvolvêlas, para além de suas configurações originais (THOMAS; BUCH, 2008, p. 261). E assim o livro encerra com a revisão teórica das abordagens trabalhadas e sua aplicabilidade em territórios onde não foram geradas, ou seja, foram aplicadas na realidade latino-americana, o que evidencia a inviabilidade de adoção de uma única perspectiva no desenvolvimento de estudos sociais da tecnologia.

Com a leitura desta obra foi possível observar que de acordo com as perspectivas teóricas utilizadas, ciência e tecnologia são tidas, muitas vezes, não como sinônimos, mas fortemente ligadas. Um exemplo dessa ligação é quando se toma a TAR num estudo 
específico em que a tecnologia apresenta suas mais variadas dimensões na sociedade. E, dependendo da perspectiva de uma pesquisa, as conceitualizações utilizadas podem sofrer modificações ou precisar de adequações dadas à trajetória e o processo de mudança tecnológica envolvidos. Bruno Latour (2009), em seu livro "Jamais fomos modernos", apresenta a artificialidade da divisão das ciências. E com base nos argumentos do livro de Thomas e Buch pode se constatar que esta artificialidade também está presente no âmbito das teorias propostas, até mesmo, por uma mesma ciência.

Da perspectiva construtivista à sociotecnica, questões contemporâneas podem ser trabalhadas se considerarmos os argumentos do livro de Thomas e Buch. Desde noções de risco e a participação pública envolvendo ciência e tecnologia, é preciso que as teorias sejam revistas e trabalhadas de modo a se complementarem, considerando a particularidade de cada região. É preciso pensar a partir do grupo em que se está inserido.

Max Weber (2004) traz a idéia de que fazer ciência implica em definir categorias e o livro de Thomas e Buch vai além, não só definindo-as, mas mostrando diferentes maneiras de como é possível trabalhá-las nos estudos sobre tecnologia. Arriscaria ainda, dizer que, a partir dos estudos da tecnologia apresentados neste livro se pode elaborar novas reflexões sobre as noções de razão instrumental e razão comunicativa habermasianas, mas isto seria outro tema, digno de outro trabalho de análise teórico-conceitual.

Um último fator que merece destaque é o fato desta obra encontrar-se escrita em língua espanhola. Isso remete a outro dado relevante envolvendo os estudos sociais da ciência e da tecnologia: a falta de referências em língua portuguesa. Não há explicação para esta situação que implica num atraso considerável para área. Não foram encontrados argumentos que justifiquem a falta de tradução dos livros e textos desta área, de outros idiomas para o português, o 
que não significa que no exterior a produção intelectual não seja significativa. Mas este é "só" mais um problema da pesquisa nacional.

O que fica da leitura da obra de Thomas e Buch vai além da afirmativa de MacKenzie e Wajcman (1985, p. 6 apud BENAKOUCHE, 1999, p. 1) que diz que para se “[...] responder à questão sobre os efeitos de uma determinada tecnologia sobre a sociedade exige que se tenha uma boa teoria de como a sociedade funciona." Em se tratando de Actos, actores y artefactos, diria ainda que ter uma boa teoria não é suficiente. É preciso ir além delas, utilizando-as de modo complementar, crítico e comparativo a assim, se terá um trabalho legítimo e original. Deveras se trata de um livro digno de reconhecimento e respeito dado sua ousadia em debater clássicos consagrados da sociologia da tecnologia e sua originalidade na proposição de novos aportes teórico-metodológicos partindo de teorias já existentes. 